\title{
EFEKTIVITAS PROGRAM PEMBELAJARAN SEKOLAH SUB T-TEP TOYOTA (TOYOTA-TECHNICAL EDUCATION PROGRAM) DI SMK NEGERI 2 PENGASIH
}

\author{
Dwi Ahmad Arif ${ }^{* 1}$ \& Herminarto Sofyan ${ }^{1}$ \\ ${ }^{1}$ Pendidikan Teknik Otomotif, Universitas Negeri Yogyakarta \\ *Email: dahmadarif@gmail.com
}

\begin{abstract}
ABSTRAK
Tujuan penelitian ini adalah: (1) mengetahui implementasi program Sekolah Sub TTEP Toyota di SMK Negeri 2 Pengasih; (2) mengetahui efektivitas program pembelajaran Sekolah Sub T-TEP Toyota di SMK Negeri 2 Pengasih ditinjau dari hasil pembelajaran siswa; (3) mengetahui faktor-faktor apa saja yang mendukung dan menghambat dalam kerjasama program Sekolah Sub T-TEP Toyota di SMK Negeri 2 Pengasih. Penelitian ini merupakan penelitian deskriptif dengan pemilihan subjek penelitian menggunakan teknik purposive sampling. Metode pengumpulan data dengan menggunakan wawancara, observasi, dokumentasi, dan angket tertutup. Hasil penelitian menunjukkan bahwa: (1) implementasi program kemitraan antara SMK Negeri 2 Pengasih dengan PT. Toyota Astra Motor diketahui telah berjalan dan terlaksana. Keempat aspek program yaitu implementasi kurikulum, pelatihan guru, kerjasama industri dalam pelaksanaan praktik kerja industri siswa, dan kerjasama donasi alat dan peralatan diketahui sudah terlaksana. Hasil penelitian menunjukan 15 indikator program dalam kategori sesuai, 3 indikator dalam kategori sangat sesuai dan 2 indikator kurang sesuai; (2) program pembelajaran Sekolah Sub T-TEP Toyota diketahui belum berhasil dan efektif, dikarenakan persentase ketuntasan belajar kelas XII TKR 1 dan 2 hanya sebesar 48,39\% dan 25,00\%; (3) faktor pendukung dalam pelaksanaan program yaitu adanya dukungan dari pemerintah, komitmen, antusiasme, sarana dan prasarana sekolah yang memadai serta kualitas SDM siswa yang bagus, sedangkan faktor penghambatnya adalah pemahaman serta keterampilan guru yang belum 100\% menguasai teknologi Toyota, keterbatasan dalam transfer teknologi serta keterbatasan biaya.
\end{abstract}

Kata kunci: implementasi, efektivitas, program pembelajaran

\section{EFFECTIVENESS OF TOYOTA SUB T-TEP SCHOOL LEARNING PROGRAM (TOYOTA-TECHNICAL EDUCATION PROGRAM) AT SMK NEGERI 2 PENGASIH}

\begin{abstract}
The aim of this study are: (1) to find out the implementation of the Toyota Sub T-TEP School program at SMK N 2 Pengasih; (2) to determine the effectiveness of the learning program of the Toyota Sub-TEP School at SMK N 2 Pengasih in terms of student learning outcomes; (3) to find out what factors support and inhibit the collaboration of the Toyota Sub-TEP School program at SMK N 2 Pengasih. This research is a descriptive study with the selection of research subjects using purposive sampling technique. Data were collected by using interviews, observation, documentation, and closed questionnaire. The results of the study showed that: (1) the implementation of the partnership program between SMK N 2
\end{abstract}


Pengasih and PT. Toyota Astra Motor is known to have been running and implemented. The four aspects of the program are the implementation of the curriculum, teacher training, industrial collaboration in the implementation of student industrial work practices, and cooperation in donating tools and equipment known to have been carried out. The results of the study show 15 program indicators in the appropriate category, 3 indicators in the very appropriate category and 2 indicators are not appropriate; (2) the learning program of the Toyota Sub T-TEP School is known to be unsuccessful and effective, because the percentage of completeness learning in class XII TKR 1 and 2 is only 48.39\% and 25.00\%; (3) supporting factors in the implementation of the program are goverment support, commitment, enthusiasm, adequate school facilities and infrastructure and good quality students, while the inhibiting factor is the understanding and skills of teachers who haven't 100\% mastered Toyota's technology, limitations in the transfer of technology and cost limitations.

Keywords: implementation, effectiveness, learning program

\section{PENDAHULUAN}

Perkembangan dunia pendidikan, khususnya pendidikan kejuruan saat ini tidak lepas dari semakin pesatnya kemajuan dibidang teknologi dan industri. Pesatnya kemajuan dibidang teknologi dan industri tersebut harusnya dibarengi dengan sumber daya manusia yang berkualitas dan kompeten dibidangnya, sehingga mampu mengembangkan serta memajukan industri kearah yang lebih baik dan mampu bersaing di era globalisasi. Dalam rangka mengembangkan serta memajukan industri yang mampu bersaing maka dibutuhkan tenaga kerja yang handal dan siap kerja. Oleh karena itu peranan pendidikan kejuruan dalam menghasilkan sumber daya manusia yang handal dan siap kerja sangatlah penting.

Menurut Clarke \& Winch dalam Sofyan (2018:10) mendefinisikan pendidikan kejuruan adalah pendidikan yang menyiapkan anak-anak muda dan remaja untuk memasuki lapangan kerja, pendidikan kejuruan adalah suatu proses yang pembelajarannya berkaitan dengan masalah teknik dan praktik. Lebih lanjut, menurut Djojonegoro (1998:34), pendidikan kejuruan adalah pendidikan yang mempersiapkan peserta didiknya untuk memasuki lapangan kerja.

Namun, fakta di lapangan menyebutkan bahwa pengangguran terbanyak justru didominasi oleh lulusan SMK. Berdasarkan sumber informasi dari berita metrotvnews.com (12 November 2018) yang memuat berita mengenai angka pengangguran di Indonesia yang didominasi oleh lulusan SMK, bahwa berdasarkan Badan Pusat Statistik (BPS) mencatat jumlah angkatan kerja di Indonesia pada Februari 2018 adalah sebanyak 133,94 juta orang. Adapun angka tersebut meningkat 2,39 juta dari jumlah angkatan kerja pada Februari 2017 
TPT (Tingkat Pengangguran Terbuka) untuk Sekolah Menengah Kejuruan (SMK) adalah yang tertinggi dibandingkan tingkat pendidikan lain, yaitu besarnya mencapai 8,92 persen.

Berdasarkan permasalahan tersebut, guna meningkatkan kualitas pendidikan dan juga mutu kompetensi lulusan siswa agar terserap dan sesuai dengan kebutuhan tuntutan dunia industri, maka perlu adanya suatu program yang dapat mensikronkan antara SMK dengan Dunia Usaha/Dunia Industri (DUDI) yaitu melalui link and match. Sejalan dengan kebijakan Departemen Pendidikan dan Kebudayaan Republik Indonesia terkait link and match guna meningkatkan relevansi Sekolah Menengah Kejuruan (SMK) dengan kebutuhan dunia kerja, dunia usaha serta dunia industri khususnya, SMK Negeri 2 Pengasih menerima tawaran kerjasama dengan PT. Toyota Astra Motor dalam bentuk program Sekolah Sub T-TEP Toyota (Toyota-Technical Education Program).

Toyota-Technical Education Program (T-TEP/Sub T-TEP) merupakan salah satu program edukasi Toyota Indonesia yang bertujuan untuk mengembangkan sumber daya siswa SMK, terutama SMK otomotif. Dengan adanya program ini diharapkan dapat menghasilkan mutu lulusan siswa SMK yang mempunyai keterampilan, kompetensi serta sikap profesionalisme kerja yang bagus dan mampu memenuhi kebutuhan industri.

Berdasarkan observasi yang sudah dilakukan selama kegiatan Praktik Lapangan Terbimbing (PLT), implementasi program Sekolah Sub T-TEP Toyota di SMK Negeri 2 Pengasih mengalami beberapa kendala atau permasalahan, yaitu pada penerapan kurikulum Toyota, fasilitas sarana dan prasarana pendukung pembelajaran, keseimbangan jumlah jam pelajaran dan juga permasalahan pada keterserapan lulusan siswa di industri. Dari hasil observasi, penerapan kurikulum Toyota dalam penyusunan RPP dan silabus pembelajaran belum sepenuhnya dijalankan oleh guru. Pembelajaran yang seharusnya memuat materi yang terdapat dalam kurikulum Toyota tidak semua diajarkan oleh guru, dikarenakan masih berpegang pada kurikulum yang ditetapkan oleh pemerintah dalam hal ini kurikulum 2013.

Kemudian fasilitas sarana dan prasarana dalam pembelajaran program Sekolah Sub TTEP Toyota (Toyota-Technical Education Program) yang ada di sekolah belum cukup untuk mendukung proses penerapan kurikulum Toyota. Dari hasil observasi awal yang sudah dilakukan, menunjukan bahwa tidak semua materi dalam muatan kurikulum Toyota terdapat bahan ajarnya di sekolah. Selain itu, jumlah lulusan atau keterserapan siswa Sekolah Sub TTEP SMK Negeri 2 Pengasih yang bekerja di Toyota Nasmoco masih tergolong rendah dan mengalami penurunan dari segi penerimaan dalam kurun waktu 4 tahun terakhir.

Lebih lanjut menurut keterangan Ketua Program Studi Teknik Otomotif, menerangkan bahwa keseimbangan jumlah jam pelajaran normatif adaptif dan produktif 
masih belum memenuhi standar yang diinginkan sesuai standar kurikulum T-TEP yaitu sekitar $\pm 60 \%: 40 \%$ untuk kelas 1,2 dan 3. Begitu pula dengan kerjasama antara SMK Negeri 2 Pengasih dengan Toyota belum sepenuhnya berjalan dengan baik. Hal ini ditandai dengan masih minimnya siswa Sub T-TEP yang diterima masuk dalam program kerjasama Prakerin di Nasmoco Toyota pada tahun ajaran 2018/2019, yaitu hanya sejumlah 5 siswa dari total 63 siswa kelas XII TKR 1 dan 2 atau hanya sebesar 7,93 \% saja yang diterima.

Berdasarkan uraian latar belakang dan juga permasalahan diatas, peneliti merasa tertarik untuk meneliti lebih lanjut mengenai implementasi dari kerjasama atau kemitraan yang dijalankan antara SMK Negeri 2 Pengasih dengan PT. Toyota Astra Motor dan juga bagaimana efektivitas dari program pembelajaran Sekolah Sub T-TEP Toyota.

\section{METODE PENELITIAN}

Penelitian ini merupakan jenis penelitian deskriptif dengan menggunakan pendekatan kualitatif dan kuantitatif dalam menentukan seberapa efektif program pembelajaran Sekolah Sub T-TEP Toyota di SMK Negeri 2 Pengasih. Penelitian ini dilaksanakan di SMK Negeri 2 Pengasih yang beralamat di Jalan KRT Kertodiningrat, Gn. Gondang, Margosari, Pengasih, Kabupaten Kulon Progo, Daerah Istimewa Yogyakarta. Waktu penelitiannya yaitu selama kurang lebih 2 bulan mulai dari bulan Januari s.d Februari 2019.

Subjek dalam penelitian ini adalah Kepala Sekolah, WKS. Kurikulum Sekolah, Kaprodi Teknik Otomotif, Guru Kompetensi TKR, Kepala Program T-TEP Toyota, dan siswa Kelas XII TKR 1 dan 2 sebanyak 63 siswa. Teknik pengumpulan data yang digunakan dalam penelitian ini adalah dengan wawancara, observasi, dokumentasi, dan angket tertutup. Sedangkan validitas instrumen dalam penelitian ini menggunakan validitas konstruksi (construct validity) sebab instrumen yang akan digunakan adalah instrumen non-test dalam bentuk angket. Validator instrumen dalam penelitian ini adalah Prof. Dr. Herminarto Sofyan, M.Pd. sebagai dosen ahli atau expert judgement. Data yang diperoleh selanjutnya dianalisis baik secara kualitatif maupun kuantitatif untuk mendeskripsikan implementasi program $\mathrm{T}$ Tep Toyota di SMK Negeri 2 Pengasih.

\section{HASIL PENELITIAN DAN PEMBAHASAN}

\section{Implementasi Program Sekolah Sub T-TEP Toyota di SMK Negeri 2 Pengasih}

Berdasarkan hasil penelitian, kemitraan atau kerjasama antara SMK Negeri 2 Pengasih dengan PT. Toyota Astra Motor dalam program Sekolah Sub T-TEP Toyota sudah terlaksana dan telah berjalan selama kurang lebih 12 tahun sejak penetapan kerjasama pada 
tanggal 7 desember 2006. Dalam program Sekolah Sub T-TEP Toyota, terdapat empat aspek yang turut mempengaruhi tingkat keefektifan program tersebut, yaitu: (1) penerapan kurikulum Toyota; (2) pelatihan tenaga pengajar (guru); (3) kerjasama industri dalam pelaksanaan Prakerin siswa; dan (4) fasilitas sarana dan prasarana program Sekolah Sub TTEP Toyota.

Hasil penelitian menunjukan bahwa dari keempat aspek program Sekolah Sub T-TEP Toyota di SMK Negeri 2 Pengasih diketahui sudah berjalan dan terlaksana. Dari keempat aspek program yang dijabarkan kedalam 20 butir indikator, hasilnya menunjukan bahwa terdapat 15 indikator yang masuk dalam kategori sesuai, 3 indikator dalam kategori sangat sesuai dan sisanya 2 indikator dalam kategori kurang sesuai. Berdasarkan hasil analisis angket tertutup, 2 indikator program yang masuk dalam kategori kurang sesuai yaitu: (1) rasio jumlah penerimaan siswa yang masuk dalam program OJT Toyota Nasmoco; dan (2) rasio jumlah tenaga pengajar (guru) yang mendapat pelatihan. Hasil penelitian ini menunjukan bahwa dari implementasi program Sekolah Sub T-TEP Toyota di SMK Negeri 2 Pengasih terdapat beberapa aspek indikator yang belum sesuai dengan keinginan pihak sekolah.

Kerjasama antara SMK Negeri 2 Pengasih dengan PT. Toyota Astra Motor dalam Program Sekolah Sub T-TEP Toyota merupakan suatu implementasi dari kebijakan link and match. Adanya kerjasama ini dapat mempercepat transfer teknologi, menambah pengetahuan siswa serta menghasilkan sumber daya lulusan SMK yang bagus dalam memenuhi kebutuhan industri. Pada penerapan kurikulum Toyota, terdapat 12 muatan dan hanya hybrid knowledge yang belum diberikan dalam pembelajaran. Dalam pelaksanaannya, penerapan kurikulum dilakukan dengan cara menyeleksi atau menyelaraskan dan mengembangkan muatan kurikulum Toyota sesuai dengan materi yang dibutuhkan sekolah, yang kemudian diaplikasikan dalam penyusunan silabus dan RPP pembelajaran teori dan praktik.

Hasil penelitan ini juga sesuai dengan apa yang diteliti oleh Sutikno \& Puspitasari (2016) yang salah satu hasil penelitiannya menyebutkan bahwa bentuk kerjasama yang dilakukan dalam hal penyusunan kurikulum, pembelajaran, dan evaluasi yang dilakukan di akhir pembelajaran kelas XII. Dalam pelaksanaan evaluasi pembelajaran bagi siswa kelas XII TKR di SMK Negeri 2 Pengasih, dilakukan dengan ujian akhir semester atau UAS yang sudah berbasis CBT (Computer Based Test) dengan menggunakan materi dan bahan ajar dari Toyota dalam penyusunan soal-soalnya. 
Kerjasama dalam donasi tools \& equipment, berdasarkan hasil penelitian diketahui bahwa pihak sekolah mendapatkan bantuan dari PT. Toyota Astra Motor berupa modul, BPR, alat-alat praktik, engine stand dan beberapa unit mobil Toyota seperti Etios Valco dan Toyota Kijang. Dalam kerjasama ini, sekolah sebagai institusi pendidikan yang ditetapkan sebagai Sekolah Sub T-TEP harus mampu memenuhi standar Toyota untuk sarana ruang belajar teori dan juga praktik. Berdasarkan hasil penelitian, sarana ruang belajar teori dan praktik di SMK N 2 Pengasih sudah sesuai dengan standar yang ditetapkan PT. Toyota Astra Motor.

Adanya kerjasama dengan industri dapat menjadi solusi bagi sekolah untuk menambah dan melengkapi fasilitas pembelajaran yang sudah ada. Selanjutnya, sebagai salah satu upaya dalam pembinaan dan pengembangan program Sekolah T-TEP/Sub T-TEP, Toyota melakukan monitoring terhadap sekolah melalui mekanisme evaluasi Kodawari TTEP/Sub T-TEP. Adanya upaya monitoring baik dari sekolah dan juga dari pihak Toyota ini menjadi sinyal baik bagi keberlangsungan kerjasama antara kedua belah pihak, yaitu SMK Negeri 2 Pengasih dengan PT. Toyota Astra Motor.

\section{Efektivitas Program Pembelajaran Sekolah Sub T-TEP Toyota di SMK Negeri 2 Pengasih Ditinjau Dari Hasil Pembelajaran Siswa}

Pembelajaran merupakan suatu proses interaksi antara peserta didik dengan pendidik dan sumber belajar pada suatu lingkungan belajar yang meliputi guru dan siswa yang saling bertukar informasi. Suatu pembelajaran tentunya perlu untuk dilakukan evaluasi atau penilaian pembelajaran untuk menentukan seberapa efektif proses pembelajaran pada suatu kelas.

Efektivitas pembelajaran dapat diartikan sebagai sejauh mana suatu pembelajaran mencapai tujuan yang direncanakan. Penentuan atas ukuran dari pembelajaran yang efektif terletak pada hasil belajarnya (ketuntasan hasil belajar). Selanjutnya, pembelajaran dapat dikatakan berhasil dan efektif apabila tingkat keberhasilan peserta didik secara klasikal mencapai $\geq 75 \%$ dari total jumlah siswa telah lulus KKM (Kriteria Ketuntasan Minimal) yang telah ditentukan (E. Mulyasa, 2014). Dalam penelitian ini, kriteria ketuntasan minimal atau KKM yang telah ditentukan oleh pihak sekolah yaitu sebesar enam puluh (KKM = $60,00)$.

Berdasarkan hasil penelitian, persentase ketuntasan belajar siswa secara klasikal di kelas XII TKR 1 yaitu sebesar 48,39\%, sedangkan untuk kelas XII TKR 2 hanya sebesar 25\%. Mengacu pada hasil tersebut, menunjukan bahwa pembelajaran di kelas XII TKR 1 dan XII 
TKR 2 belum behasil atau belum efekif. Jadi, dapat ditarik kesimpulan bahwa program pembelajaran Sekolah Sub T-TEP Toyota di SMK Negeri 2 Pengasih ditinjau dari hasil pembelajaran siswa belum efektif. Ketidakefektifan tersebut bisa jadi disebabkan oleh adanya faktor penghambat atau kendala dalam proses pembelajarannya, baik dari segi materi yang disusun atau penyampaian guru yang belum maksimal.

\section{Faktor Pendukung dan Penghambat Dalam Kerjasama Program Sekolah Sub T-TEP Toyota di SMK Negeri 2 Pengasih}

Faktor pendukung dalam suatu program atau kegiatan, biasanya mempunyai pengaruh besar terhadap berkembangnya suatu program kearah yang lebih baik. Berdasarkan hasil keseluruhan wawancara dengan pihak sekolah maupun industri, maka peneliti dapat menyimpulkan bahwa yang menjadi faktor pendukung dalam kemitraan atau kerjasama program Sekolah Sub T-TEP antara SMK N 2 Pengasih dan PT. Toyota Astra Motor adalah adanya dukungan dari pemerintah terkait link and match, komitmen sekolah dan industri, antusiasme dari siswa dan guru, sarana dan prasarana sekolah yang sudah memadai serta kualitas SDM siswa yang bagus.

Adanya dukungan dari pemerintah terkait kebijakan link and match dapat mendukung jalannya suatu program, karena dengan adanya dukungan tersebut mampu menjadi bagian dari legalitas kerjasama antara kedua belah pihak. Selanjutnya adalah komitmen sekolah dan industri. Komitmen akan menimbulkan kekuatan untuk selalu terikat dengan perjanjian dalam suatu perkumpulan (Yuswono, dkk, 2014). Oleh karena itu, komitmen dari pihak sekolah maupun industri dapat menjadi sinyal positif atau bentuk keseriusan dari kerjasama yang sedang dijalankan bersama, apalagi didukung oleh antusiasme dari para siswa dan guru terkait program tersebut

Selanjutnya, faktor penghambat dalam program Sekolah Sub T-TEP bisa menjadi salah satu sebab suatu program atau kegiatan menjadi terkendala dalam pelaksanaannya atau mengalami beberapa permasalahan. Dari hasil wawancara, observasi dan juga dokumentasi, maka peneliti dapat menyimpulkan bahwa yang menjadi faktor penghambat atau kendala dalam kemitraan atau kerjasama program Sekolah Sub T-TEP Toyota adalah pemahaman dan keterampilan guru yang belum 100\% menguasai teknologi Toyota, keterbatasan dalam transfer teknologi, keterbatasan biaya pemeliharaan alat peraga serta ketidaktersediaan biaya akomodasi dalam pelaksanaan monitoring sekolah kepada siswa OJT Nasmoco.

Pemahaman serta keterampilan guru sangat berpengaruh terhadap hasil suatu pembelajaran, karena guru sebagai tenaga kependidikan menjadi salah satu media informasi 
bagi siswa untuk memperoleh ilmu selama pembelajaran di kelas. Jika guru tidak mampu atau belum bisa $100 \%$ menguasai teknologi dari Toyota, maka output siswa yang dihasilkan juga tidak bisa sesuai dengan yang diharapkan. Kemudian, keterbatasan dalam transfer teknologi juga dapat menghambat proses belajar siswa sehingga pengetahuan dan keterampilan siswa mengenai teknologi Toyota menjadi kurang.

\section{SIMPULAN DAN SARAN}

\section{Simpulan}

Berdasarkan hasil penelitian dan pembahasan, penelitian ini dapat diambil kesimpulan sebagai berikut:

1. Implementasi program kemitraan atau kerjasama antara SMK Negeri 2 Pengasih dengan PT. Toyota Astra Motor diketahui telah berjalan dan terlaksana. Keempat aspek dalam program yaitu implementasi kurikulum, pelatihan guru, kerjasama industri dalam Prakerin siswa Nasmoco, dan kerjasama donasi tools and equipment antara SMK Negeri 2 Pengasih dengan PT. Toyota Astra Motor diketahui sudah terlaksana. Hasil penelitian menunjukan 15 indikator aspek program Sekolah Sub T-TEP Toyota dalam kategori sesuai, 3 indikator dalam kategori sangat sesuai dan 2 indikator kurang sesuai. Indikator program yang masuk dalam kategori kurang sesuai yaitu: (1) rasio jumlah penerimaan siswa yang masuk dalam program OJT Toyota Nasmoco; dan (2) rasio jumlah tenaga pengajar (guru) yang mendapat pelatihan.

2. Efektivitas program pembelajaran Sekolah Sub T-TEP Toyota di SMK Negeri 2 Pengasih ditinjau dari hasil pembelajaran siswa diketahui belum berhasil dan efektif. Hasil dari analisis data yang diperoleh menunjukan bahwa ketuntasan belajar pada Kelas XII TKR 1 sebesar 48,39\%, sedangkan Kelas XII TKR 2 hanya sebesar $25 \%$.

3. Faktor pendukung dalam kemitraan atau kerjasama program Sekolah Sub T-TEP Toyota antara SMK N 2 Pengasih dengan PT. Toyota Astra Motor yaitu adanya dukungan dari pemerintah terkait link and match, komitmen sekolah dan industri, antusiasme dari siswa dan guru, sarana dan prasarana sekolah yang sudah memadai serta kualitas SDM siswa yang bagus. Sedangkan kendala atau yang menjadi penghambat dalam kerjasama program yaitu pemahaman dan keterampilan guru yang belum 100\% menguasai teknologi Toyota, keterbatasan dalam transfer teknologi, keterbatasan biaya pemeliharaan alat 
peraga serta ketidaktersediaan biaya akomodasi dalam pelaksanaan monitoring sekolah kepada siswa Prakerin Nasmoco.

\section{Saran}

Berdasarkan hasil penelitian yang diperoleh, maka peneliti dapat memberikan beberapa saran kepada pihak SMK Negeri 2 Pengasih dan juga PT. Toyota Astra Motor agar kerjasama yang telah berjalan bisa menjadi lebih baik lagi, yaitu sebagai berikut:

1. Kemitraan atau kerjasama dalam program Sekolah Sub T-TEP yang sudah berjalan perlu ditingkatkan dan diperbaiki lagi agar kedepan dapat menghasilkan lulusan siswa yang sesuai dengan harapan semua pihak serta program-program yang masih menemui kendala dapat segera teratasi.

2. Sekolah harus membangun komunikasi dengan pihak industri mengenai kompetensi di dunia kerja dan juga sebaliknya, sehingga dapat menjadi bahan acuan dan masukan dalam pembelajaran di sekolah.

3. Sekolah perlu membuat laporan dalam bentuk buku atau hardfile dari pelaksanaan monitoring siswa Prakerin Nasmoco setiap tahunnya, sehingga dapat dijadikan sebagai bahan acuan untuk mengetahui sejauh mana progress atau kemajuan dari kerjasama yang sudah berjalan.

4. Industri perlu meningkatkan monitoring dan evaluasi kepada pihak sekolah agar pembinaan dan pengembangan terhadap sekolah-sekolah yang tergabung dalam program Sekolah Sub T-TEP Toyota dapat cepat berkembang dan transfer teknologinya juga semakin baik.

\section{DAFTAR PUSTAKA}

Direktorat Pembinaan Sekolah Menengah Kejuruan. (2017). Tatakelola Pelaksanaan Teaching Factory. Jakarta: Direktorat Pembinaan Sekolah Menengah Kejuruan. Djojonegoro, W. (1998). Pengembangan Sumber Daya Manusia Melalui Sekolah Menengah Kejuruan. Jakarta: Jayakarta Agung Offset.

Mulyasa, E. (2014). Guru Dalam Implementasi Kurikulum 2013. (Cetakan Pertama) Bandung: Remaja Rosdakarya.

Sofyan, H. (2018). Pendidikan Teknologi Kejuruan. (Edisi Pertama) Yogyakarta: UNY Press. 
Sugiyono. (2017). Metode Penelitian Kuantitatif, Kualitatif, dan R\&D. (Cetakan Ke- 26) Bandung: Aflabeta.

Sutikno, T.A. \& Puspitasari, D.E. (2016). Studi Kemitraan SMK Dengan Dunia Usaha dan Industri (Studi Kasus Di SMK PGRI 3 Malang).Jurnal Teknologi Elektro dan Kejuruan, (26), 2, pp. 82-91.

Suwandi. (2016). Analisis Studi Kebijakan Pengelolaan Guru SMK Dalam Rangka Peningkatan Mutu Pendidikan. Jurnal Pendidikan Teknologi dan Kejuruan, Volume 23, Nomor 1.

TAM. Toyota Technical Education Program. Sumber:http://www.toyota.astra.co.id/socialresponsibility/education. Diakses pada tanggal 16 Desember 2019.

Undang-Undang Nomor 20 Tahun 2003 Tentang Sistem Pendidikan Nasional.

Yuswono, L.C., Martubi \& Sukaswanto. (2014). Profil Kompetensi Guru Sekolah Menengah Kejuruan Teknik Otomotif Dikabupaten Sleman. Jurnal Pendidikan Teknologi dan Kejuruan, Volume 22, Nomor 2. 